\title{
ULTRA-LOW DOSE VERSUS HIGH DOSE INTRATHECAL ANAESTHESIA FOR ELECTIVE LOWER LIMB ARTHROPLASTY
}

Adshead D ${ }^{1}$, Spilsbury $Z^{2}$, White $S^{3}$, Tighe $S^{4}$

${ }^{1}$ Specialty Trainee, Anaesthetics, Yorkshire and the Humber Deanery

${ }^{2}$ Core Trainee, Anaesthetics, Countess of Chester Hospital Foundation NHS Trust, Chester, UK

${ }^{3}$ Specialty Trainee, Anaesthetics, North West (Mersey) Deanery

${ }^{4}$ Consultant Anaesthetist , Countess of Chester Hospital Foundation NHS Trust, Chester, UK

\section{Introduction}

We compared a low dose intrathecal technique with a conventional higher dose ${ }^{1}$, to minimize cardiovascular effects, maximize early mobilization, minimise length of hospital stay and reduce costs for elective joint arthroplasty.

\section{Methods}

R\&D approval was obtained. Ethical approval was not required. 30 of ST's patients having lower limb arthroplasty had intrathecal levobupivacaine $5.0-7.0 \mathrm{mg}(1.0-1.4 \mathrm{mls}$ of $0.5 \%)$ with fentanyl $15 \mu \mathrm{g}$, made up to $3 \mathrm{mls}$ with saline (LD group) ${ }^{2}$, his established routine practice. One litre/hour of Ringer's Lactate was given, plus ephedrine and/or metaraminol to maintain mean arterial pressure (MAP) greater than $80 \%$ of the preoperative mean. Sedation was with $\mathrm{TCl}$ propofol $0.5-1.5 \mu \mathrm{g} / \mathrm{ml}$. Hospital records were retrospectively audited and compared with 30 patients having $\geq 12.5 \mathrm{mg}$ ( $2.5 \mathrm{mls}$ of $0.5 \%$ ) levobupivacaine or bupivacaine without adjunct (HD group) during the same period (2016) by other anaesthetists.

\section{$\underline{\text { Results }}$}

See table 1. The median dose in the LD group was $6 \mathrm{mg}$ for surgery lasting up to $135 \mathrm{mins}$. Nineteen of the $30 \mathrm{LD}$ patients had only 5-6 mg levobupivacaine. None required additional analgesia and there were no GA conversions. In the HD group, the median dose was $13.5 \mathrm{mg}$. The LD group received less IV fluid, had a higher MAP and a lower drop in $\mathrm{Hb}$ than those in the HD group. Ten units of blood were transfused in the HD group for 5 patients, compared to none in the LD group (very nearly significant).

LD patients mobilized more quickly (13 in 4hrs or less) than those in the HD group and mean length of hospital stay was 2 days shorter. Three patients required bladder catheterisation in the HD group, compared to none in the LD group (insignificant).

The mean surgical and theatre recovery times were longer
Table 1. Low (LD) versus high (HD) dose intrathecal anaesthesia for lower limb arthroplasty. Mean (SD) or number (proportion)

\begin{tabular}{lccc}
\hline & $\begin{array}{c}\text { LD group } \\
(\mathrm{n}=30)\end{array}$ & $\begin{array}{c}\text { HD group } \\
(\mathrm{n}=30)\end{array}$ & p value \\
\hline Age: years & $72.4(8.9)$ & $71.9(14.5)$ & 0.3588 \\
ASA 1/2/3/4: $\mathrm{n}$ & $4 / 18 / 7 / 1$ & $2 / 17 / 10 / 1$ & 0.7471 \\
Hip/Knee Arthroplasty: $\mathrm{n}$ & $15 / 15$ & $15 / 15$ & 1.0000 \\
Surgical Time: minutes & $81.3(21.1)$ & $102.2(19.2)$ & 0.0002 \\
Recovery Unit Time: minutes & $31.4(10.6)$ & $45.1(29.1)$ & 0.0183 \\
Levobupivacaine Dose: $\mathrm{mg}$ & $6.0(0.5)$ & $13.5(1.0)$ & 0.0001 \\
Vasoconstrictors: $\mathrm{n}$ & $6(20 \%)$ & $16(53 \%)$ & 0.0150 \\
Fluid: litres & $1.3(0.4)$ & $1.6(0.5)$ & 0.0314 \\
Minimum MAP: $\mathrm{mmHg}$ & $73.1(11.2)$ & $67.0(11.9)$ & 0.0473 \\
Drop in Haemoglobin: $\mathrm{gL} \mathrm{L}^{-1}$ & $15.7(6.8)$ & $25.1(17.5)$ & 0.0078 \\
Transfusion: $\mathrm{n}$ & $0(0 \%)$ & $5(17 \%)$ & 0.0522 \\
Catheter: $\mathrm{n}$ & $0(0 \%)$ & $3(10 \%)$ & 0.2373 \\
Time to Mobilisation: hours & $7.6(5.9)$ & $18.8(9.5)$ & 0.0001 \\
Length of Stay: days & $2.9(1.4)$ & $4.9(3.1)$ & 0.0001 \\
Additional Analgesia: $\mathrm{n}$ & $0(0 \%)$ & $0(0 \%)$ & 1.0000 \\
GA conversion: $\mathrm{n}$ & $0(0 \%)$ & $0(0 \%)$ & 1.0000 \\
Estimated Cost Savings: $\mathrm{f} /$ year & 300,000 & &
\end{tabular}
in the HD group. ST worked predominantly with one of five surgeons, who had faster operating times. However, the mean length of stay after intrathecal anaesthesia for all elective arthroplasties was not significantly different between surgeons in 2016.

If all 350 elective lower limb arthroplasties performed per annum had an LD technique, our Trust could possibly save at least $£ 280,000$ per annum in reduced bed days ( $£ 400 /$ day) and $£ 20,000$ in blood transfusions ( $£ 165 /$ unit), $£ 300,000$ per annum in total.

\section{Conclusions}

We reduced the levobupivacaine dose by $>50 \%$, allowing earlier mobilisation, a two day reduction in hospital stay and significant potential cost savings. MAP was higher, IV fluid volumes were less, with a smaller drop in $\mathrm{Hb}$, a trend to lower transfusions and reduced vasoconstrictor requirements, compared to the HD technique. However, surgical times were $20 \%$ shorter in the LD group and although this could have influenced results, this is unlikely to have been a major factor. Conventional intrathecal doses are probably excessive.

A randomised controlled prospective trial is indicated to prove this assertion. The same technique is applicable to anaesthesia for fractured neck of femur and could contribute to a reduction in mortality, because this been related to avoidance of hypotension and intrathecal dose of local anaesthetic ${ }^{3}$.

\section{References}

1. Glaser $\mathrm{Cl}$, Marhofer $\mathrm{P}$, et al. Levobupivacaine versus racemic bupivacaine for spinal anesthesia. Anesthesia and Analgesia 2002;94:194-8.

2. Ben-David B, Frankel R, et al. Minidose bupivacaine-fentanyl spinal anesthesia for surgical repair of hip fracture in the aged. Anesthesiology 200;92:6-10.

3. White SM, Moppett IK, Griffiths R et al. Secondary analysis of outcomes after 11,085 hip fracture operations from the prospective UK Anaesthesia. Sprint Audit of Practice (ASAP-2). Anaesthesia 2016; 71: 506-14. 